\title{
Adhesion of Human Osteoblasts Cell on CrN Thin Film Deposited by Cathodic Arc Plasma Deposition
}

\author{
Vuong Hung Phamª Sun Kyu Kim ${ }^{\mathrm{b} *}$ \\ ${ }^{a}$ Department of Immunology and Biomedicine, University of Ulsan, Ulsan 680-749, Korea \\ ${ }^{b}$ School of Materials Science and Engineering, University of Ulsan, Ulsan 680-749, Korea
}

(Received March 12, 2009; revised April 10, 2009; accepted October 30, 2009)

\begin{abstract}
Interaction between human osteoblast (hFOB 1.19) and $\mathrm{CrN}$ films was conducted in vitro. CrN films were produced by cathodic arc plasma deposition. The surface was characterized by atomic force microscopy (AFM). $\mathrm{CrN}$ films, glass substrates and TiN films were cultured with human osteoblasts for 48 and 72 hours. Actin stress fiber patterns and cell adhesion of osteoblasts were found less organized and weak on CrN films compared to those on the glass substrates and the TiN films. Human osteoblasts also showed less proliferation and less distributed microtubule on $\mathrm{CrN}$ films compared to those on glass substrates and TiN films. Focal contact adhesion was not observed in the cells cultured on $\mathrm{CrN}$ films, whereas focal contact adhesion was observed well in the cells cultured on glass substrates and TiN films. As a result, the $\mathrm{CrN}$ film is a potential candidate as a surface coating to be used for implantable devices which requires minimal cellular adhesion.

Keywords: Human osteoblast, CrN film, Cell adhesion, surface coating, Cytoskeleton
\end{abstract}

\section{Introduction}

Chromium nitride $(\mathrm{CrN})$ films belong to an interesting group of transition metal nitrides films ${ }^{1}$. Like TiN films, CrN films are considered as hard coating materials. Previous studies have focused on TiN thin film as a hard coating to enhance osteoblast cells adhesion ${ }^{2,3)}$. CrN films have many advantages, such as wear resistance, corrosion resistance, oxidation resistance and low electrical resistivity ${ }^{4-8)}$. The softer and less brittle $\mathrm{CrN}$ with a microhardness comparable to TiN has many advantages if one needs to protect relatively soft substrates such as stainless steels, unhardened steels, light metals and light metal alloys9). Numerous studies have been done on the application of $\mathrm{CrN}$ films on tools and casting mold dies $^{10)}$, diffusion barriers ${ }^{7)}$ and solar selective absorbers ${ }^{11}$. Concerning cell-based devices, there are two common strategies for designing artificial surfaces in biological application. One involves creating surfaces not allowing the cellular adhesion ${ }^{12,13}$. The other, a more common strategy, is to create surfaces promoting cell adhesion ${ }^{14)}$.

*Corresponding author. E-mail : skim@ulsan.ac.kr
Williams et al. investigated the effect of $\mathrm{CrN}$ and $\mathrm{CoCr}$ wear products on the viability of fibroblast and macrophage cells ${ }^{15}$. Their report indicated the $\mathrm{CoCr}$ wear particles reduced cell viability more than $\mathrm{CrN}$ wear particles. In this work, we evaluated the osteoblast cell adhesion to $\mathrm{CrN}$ films deposited by cathodic arc plasma deposition. The choice of cathodic arc plasma deposition is from the fact that good adhesion between the coated layer and the substrate can be achieved. For comparative purpose, TiN film, which was found as a promoting cellular adhesion surface in the previous work was used as a reference surface $^{2,3)}$.

\section{Experimental}

Standard round glass coverslips of $12 \mathrm{~mm}$ (Marienfeld, Germany) were used as substrates. Prior to deposition, the substrates were ultrasonically cleaned with ethanol (95\%) for $20 \mathrm{~min}$ and then dried by $\mathrm{Ar}$ gas. Finally, they were loaded into the deposition chamber. The detailed experimental procedures were described elsewhere $^{16)}$. $\mathrm{Cr}$ and $\mathrm{Ti}$ cathodes were used for deposition of $\mathrm{CrN}$ and TiN films, respectively. The 
arc current was kept in constant at $60 \mathrm{~A}$ for deposition of $\mathrm{CrN}$ films, while it was $45 \mathrm{~A}$ for deposition of TiN films. Deposition was done without applying bias potential at $200^{\circ} \mathrm{C}$. Surface roughness was measured by AFM. The apparatus used was thermomicroscope (CP-research system) with a cantilever (ARROW-CONTRO50, Nanoworld).

Human osteoblasts (hFOB 1.19, ATCC, CRL11372) were used as a model for studying the interaction between the cell and the surface. The cells were maintained in Dulbecco's modified Eagles Medium (DMEM) containing 10\% fetal bovine serum and $1 \%$ antibiotics at $37^{\circ} \mathrm{C}$ in humidified air and $5 \% \mathrm{CO}_{2}$.

For actin staining, attached cells were rinsed twice with phosphate buffer saline (PBS), fixed with $4 \%$ paraformaldehyde for $15 \mathrm{~min}$. Then they were permeabilized with $0.1 \%$ Triton X-100 in PBS before and after PBS washing. They were stained with Alexa-flour phallodin 488 (Invitrogen) for $30 \mathrm{~min}$.

Adherence of the cells on the thin films was determined by counting in seven randomly chosen fields of view at magnification 100 under an optical microscope (Axiovert 135). For the cell adherence analysis, the $t$-test was used to assess the statistical significance of results between surfaces. The statistical analysis was performed with the software GraphPad
Prism 4 at the confidence level of $95 \%$. A probability value of $p<0.05$ was considered significant.

For tubulin staining, anti-tubulin monoclonal antibody (Sigma-Aldrich) was used as the primary antibody. Alexa 488 goat anti-mouse (Invitrogen) was used as the secondary antibody. Cells were rinsed twice with phosphate buffer saline (PBS), and fixed with $4 \%$ paraformaldehyde for $10 \mathrm{~min}$. Then they were permeabilized with $0.1 \%$ Triton X-100 in PBS after PBS washing, blocked with $1 \%$ bovine serum albumin (BSA) and stained with the primary antibody for $30 \mathrm{~min}$. They were rinsed again with PBS and then stained with the secondary antibody for $30 \mathrm{~min}$. Cell proliferation was observed by visualization of the immunofluorescent cells after 48 and $72 \mathrm{~h}$ of incubation.

For focal contact adhesion analysis, anti-vinculin (hVIN-1, Sigma-Aldrich) was used as the primary antibody, and Alexa 488 goat anti-mouse (Invitrogen) as the secondary antibody. Cells were rinsed twice with PBS, and fixed with $4 \%$ paraformaldehyde for $10 \mathrm{~min}$. Then the cells were permeabilized with $0.1 \%$ Triton X-100 in PBS, blocked with 1\% BSA and stained with the primary antibody for $45 \mathrm{~min}$. The cells were then rinsed with PBS and stained with the secondary antibody for $30 \mathrm{~min}$. All visualization of the stained cell was done by a confocal microscope (Olympus $1 \times 81$ ).

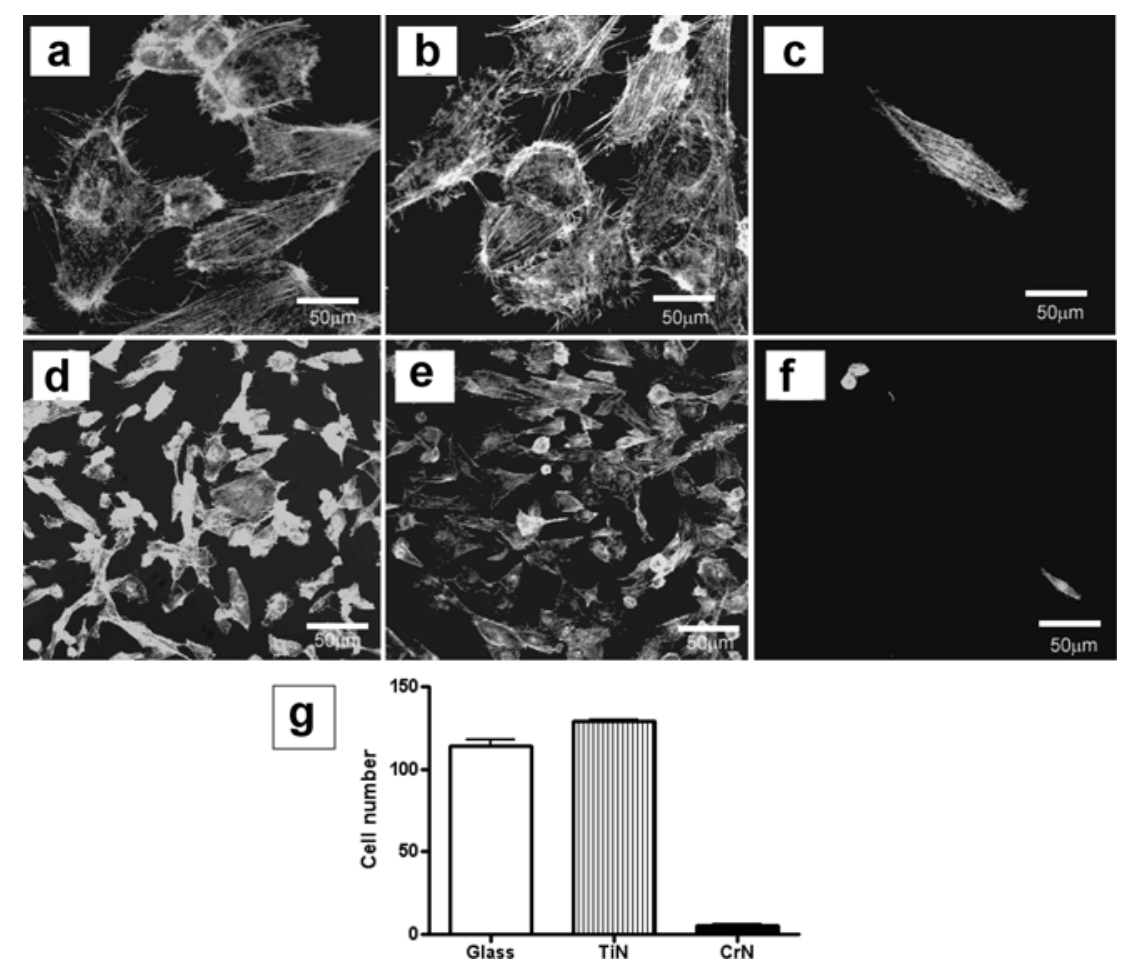

Fig. 1. Cytoskeleton analysis of osteoblast on tested specimens and its cellular adhesion after $48 \mathrm{~h}$ of culturing. (a and d: glass substrate, b and e: TiN film, c and f: CrN film. (a-c) Actin cytoskeleton, (d-f) visualization of cell adhesion, (g) quantification of cell adhesion. 


\section{Results and Discussion}

Using AFM, the average surface roughness of $\mathrm{CrN}$ film, TiN film and glass substrate were inspected. The surface roughness of $\mathrm{CrN}$ and $\mathrm{TiN}$ film was $0.725 \mathrm{~nm}$ and $0.480 \mathrm{~nm}$, respectively while the value on glass substrate was only $0.161 \mathrm{~nm}$.

Examination of actin cytoskeleton organization of the cells focused on the analyzing the cells cultured on the films on which stress fibers were formed (Fig. 1a, b, c). Actin stress fibers were oriented in parallel direction with the main cellular axis on the glass substrates and TiN films, whereas actin stress fibers were almost invisible in the cells cultured on $\mathrm{CrN}$ films. Interestingly, filopodia evidences were observed in the cells cultured on glass substrates and TiN films, whereas filopodia evidences were not detected in the cells cultured on CrN films.
Fig. 1d, e, f, and $g$ show the visualization and quantification of cell adhesion on three tested surfaces after $48 \mathrm{~h}$ of incubation. The number of attached cells was significantly lower on the $\mathrm{CrN}$ films than on the glass substrates $(p<0.05)$ or the TiN films $(p<0.05)$.

The cell proliferation on the films and the glass substrates after 48 and $72 \mathrm{~h}$ of incubation is shown in Fig. 2. Cells on the TiN films and glass substrates considerably more proliferated than on the $\mathrm{CrN}$ films after $48 \mathrm{~h}$ of culturing (Fig. 2a, b, c). It is also clear from the micrographs that the cells nearly reached the confluence after $72 \mathrm{~h}$ of incubation on the TiN films (Fig. 2h) and the glass substrates (Fig. 2g), whereas cells were far from obtaining the confluence after $72 \mathrm{~h}$ of culturing on the CrN films (Fig. 2i).

Fig. 2(d-f) and (k-m) shows the microtubule organization of cells on glass substrates, TiN films

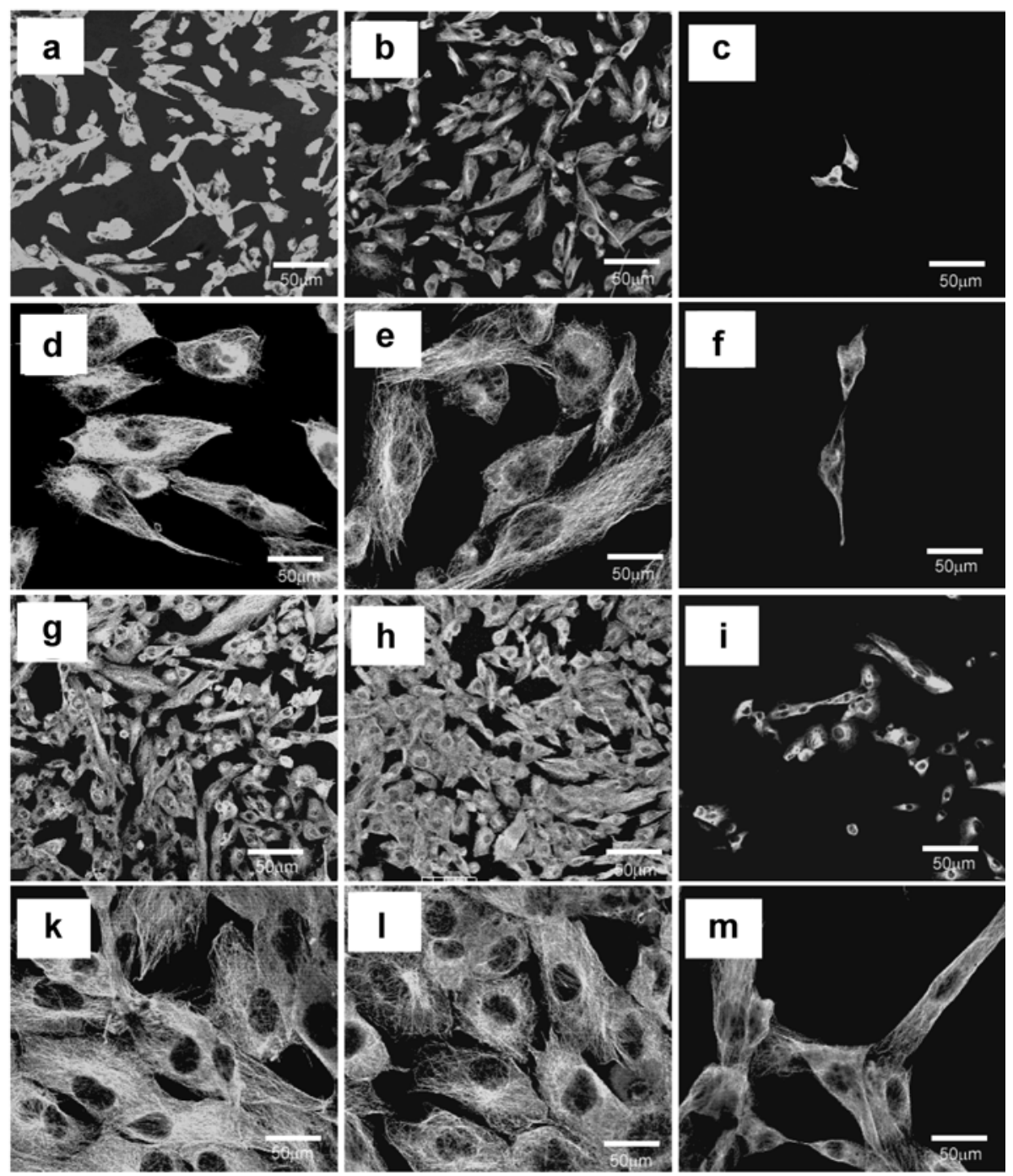

Fig. 2. Cell proliferation and microtubule cytoskeleton of cells on the tested specimens after 48 and $72 \mathrm{~h}$ of culturing (a, d, g, and k) glass substrate, (b, e, h and I) TiN film, (c, f, i, and m) CrN film, (a-f) $48 \mathrm{~h}$ of incubation, (gm) $72 \mathrm{~h}$ of incubation. 


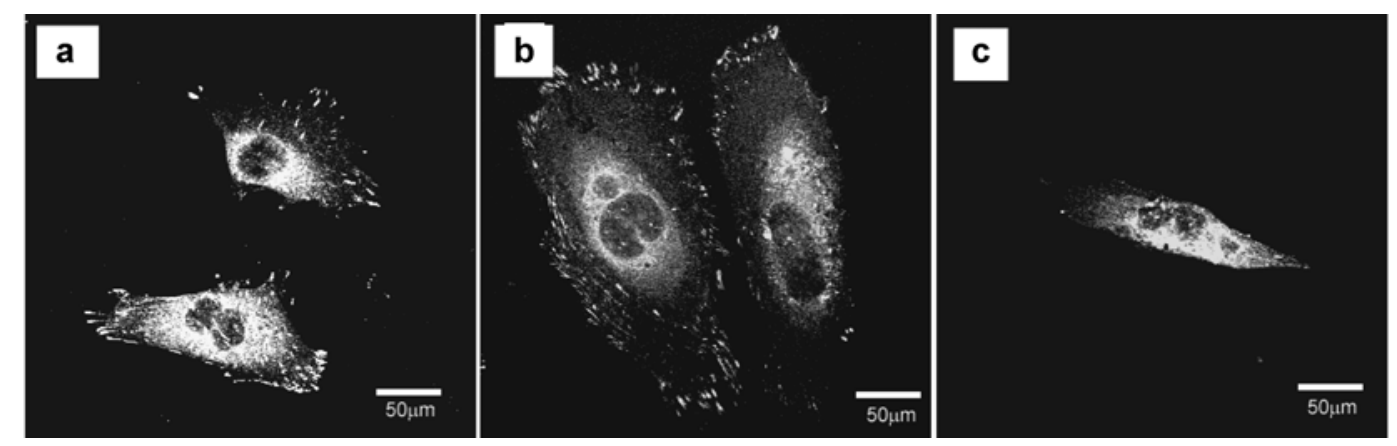

Fig. 3. Fluorescent image focal adhesion of cells on the films after $48 \mathrm{~h}$ of incubation. (a) glass substrate, (b) TiN film. (c) $\mathrm{CrN}$ film.

and $\mathrm{CrN}$ films after 48 and $72 \mathrm{~h}$ of incubation. As shown in Fig. 2, microtubules of osteoblasts were expanded on the TiN films and the glass substrates, whereas cells on the $\mathrm{CrN}$ films were narrower and had a lower expression of tubulin represented by less microtubles in the cells (Fig. 2f, $\mathrm{m}$ ). We found much difference in the development of microtubules between the TiN films or glass substrates and $\mathrm{CrN}$ films after 48 and $72 \mathrm{~h}$ of incubation.

Fig. 3 shows the focal contact adhesion of osteoblasts on the glass substrates and the films. Focal contact adhesions were found on the glass substrates and the TiN films. However, focal contact adhesion was not formed in the cells cultured on $\mathrm{CrN}$ films. Focal adhesions are signaling pathways resulting in the regulation of cell behavior such as cell adhesion and spreading ${ }^{17)}$. In the cell culture, the medium containing serum proteins does not directly adhere to the substratum surface but to an adsorbed layer of serum components $^{18)}$. CrN surface chemistry might inhibit absorption of extracellular matrix (ECM) protein from cultured medium which made the cells not able to reorganize these molecules to access the ligands for integrin receptors and recruit these receptors into focal adhesion plaques which is prerequisite for delivery of signal ensuring the attachment and growth of anchorage-dependent cells ${ }^{19,20)}$.

Cathodic arc plasma deposition produced many particles thus cause the surface of the TiN and $\mathrm{CrN}$ films to be rougher than that of glass substrates. In this paper, we found that cell adhered less and proliferated less on $\mathrm{CrN}$ films than the corresponding glass substrates and TiN films. Actin cytoskeleton and microtubule cytoskeleton analysis indicated that cells were not able to develop well organized actin cytoskeleton and well distributed microtubule cytoskeleton on $\mathrm{CrN}$ films, suggesting lack of adhesion strength and spreading of the cell.

It is interesting to compare our results with the work of Cai et $a .^{21)}$. They found measurably higher osteoblast proliferation on rough (chitosan/gelatin) modified titanium surfaces compared with that of titanium films. However, osteoblasts were found to attach and proliferate at similar rates on CoCrMo and stainless steel substrates, even though these two surfaces had significantly different roughness ${ }^{22}$. In our study, the CrN films revealed a much lower number of attached osteoblasts compared to the glass substrates and TiN films, even though $\mathrm{CrN}$ films had high degree of roughness. The actin cytoskeleton patterns, microtubules organization and focal contact adhesions were also reduced in the cells cultured on $\mathrm{CrN}$ films.

This is probably due to the effects of surface charge and surface chemistry of the $\mathrm{CrN}$ thin films. Den Braber et $a l^{23)}$ and Chien et $a{ }^{24)}$ have shown that characteristics such surface charge and chemistry have influence on the conformation of the adsorption of proteins on the substrates. In the cell culture, the medium containing serum proteins do not directly adhere to the substratum surface but to the adsorbed layer of the serum components which is crucial to cell adhesion.

\section{Conclusions}

In this study, osteoblast response to glass substrates, $\mathrm{TiN}$ and $\mathrm{CrN}$ thin films were evaluated. Actin stress fiber patterns and cell attachments on $\mathrm{CrN}$ films were much lower than those on the TiN films and the glass surfaces. Microtubule organizations, proliferation and focal contact adhesions were also much reduced in the cells cultured on the $\mathrm{CrN}$ films suggesting that $\mathrm{CrN}$ coatings have the potential for designing surfaces for minimizing cells adhesion. 


\section{Acknowledgement}

This research was supported by the 2009 University of Ulsan Research Fund.

\section{References}

1. H. Y. Chen, C. J. Tsai, F. H. Lu, Surf. Coat. Technol., 184 (2004) 69.

2. H. H. Huang, C. H. Hsu, S. J. Pan, J. L. He, C. C. Chen, T. L. Lee, Appl. Surf. Sci., 244 (2005) 252.

3. V. H. Pham, S. K. Kim, V. V. Le, B. S. Kwon, J. Kor. Inst. Surf. Eng., 41 (2008) 264.

4. A. Aubert, R. Gillet, A. Gaucher, J. P. Terrait, Thin Solid Films, 108 (1983) 165.

5. O. Knotek, W. Bosch, M. Atzor, W. D. Münz, D. Hofmann, J. Goebel., High Temp. High Press, 18 (1986) 435.

6. A. Schröer, W. Ensinger, G. K. Wolf, Mater. Sci. Eng. A., 140 (1991) 625.

7. M. A. Nicolet, Thin Solid Films, 52 (1978) 415.

8. B. Navinšek, P. Panjan, I. Milošev, Surf. Coat. Technol., 97 (1997) 182.

9. E. J. Bienk, H. Reitz, M. J. Mikkelsen, Surf. Coat. Technol., 76-77 (1995) 474.

10. F. H. Lu, H. Y. Chen, Thin Silid Films, 398-399 (2001) 368.

11. C. Gantier, J. Machet, Thin Solid Films, 295 (1997) 43.

12. J. Lee, B. S. Kang, B. Hicks, T. F. Chancellor, Jr., B. H. Chu, H. T. Wang, B. G. Keselowsky, F. Ren,
T. P. Lele, Biomaterials, 29 (2008) 3743.

13. A. D. Cook, J. S. Hrkach, N. N. Gao, I. M. Johnson, U. S. Pajvani, S. M. Cannizzaro, R. Langer, J. Biomed. Mater. Res., 35 (1997) 513.

14. D. V. Shtansky, N. A. Gloushankova, I. A. Bashkova, M. A. Kharitonova. T. G. Moizhess, A. N. Sheveiko, F. V. Kiryukhantsev-Korneev, M. I. Petrzhik, E. A. Levashov, Biomaterials, 27 (2006) 3519.

15. S. Wliliams, G. Isaac, P. Hatto. M. H. Stone, E. Ingham, J. Fisher, J. Arthroplasty, 19 (2004) 112.

16. S. K. Kim, P. V. Vinh, J. H. Kim, T. Ngoc, Surf. Coat. Technol., 200 (2005) 1391.

17. A. Bershadsky, M. Kozlov, B. Geiger, Curr. Opin. Cell Biol., 18 (2006) 472.

18. J. A. Jansen, J. P. van der Waerden, K. de Groot, J. Invest. Surg., 2 (1989) 29.

19. S. Huang, C. S. Chen, D. E. Ingber, Mol. Biol. Cell, 9 (1998) 3179.

20. A. J. Garcia, M. D. Vega, D. Boettiger, Mol. Biol. Cell, 10 (1999) 785.

21. K. Cai, A. Rechtenbach, J. Hao, J. Bossert, K. D. Jandt, Biomaterials, 26 (2005) 5960.

22. C. Hendrich, U. Noth, U. Stahl, F. Merklein, C. P. Rader, N. Schütze, R. Thull, R. S. Tuan, J. Eulert, Clin. Orthopedics Relat. Res., 394 (2002) 278.

23. E. T. den Braber, J. E. de Ruijter, L. A. Ginsel, A. F. von Recum, J. A. Jansen, Biomaterials, 17 (1996) 2037.

24. C. C. Chien, K. T. Liu, J. G. Duh, K. W. Chang, K. H. Chung, Dental. Mater., 24 (2008) 986. 